Article

\title{
"It's That Kind of Place Here": Solidarity, Place-Making and Civil Society Response to the 2015 Refugee Crisis in Wales, UK
}

\author{
Taulant Guma ${ }^{1, *}$, Michael Woods ${ }^{2}$, Sophie Yarker ${ }^{3}$ and Jon Anderson ${ }^{4}$ \\ ${ }^{1}$ School of Applied Sciences, Edinburgh Napier University, Edinburgh, EH11 4BN, UK; E-Mail: taulant.guma@gmail.com \\ 2 Department of Geography and Earth Sciences, Aberystwyth University, Ceredigion, SY23 3DB, UK; \\ E-Mail:m.woods@aber.ac.uk \\ ${ }^{3}$ School of Social Sciences, University of Manchester, Manchester, M13 9PL, UK; E-Mail: sophie.yarker@manchester.ac.uk \\ ${ }^{4}$ School of Geography and Planning, Cardiff University, Cardiff, CF10 3WA, UK; E-Mail: andersonj@cardiff.ac.uk \\ * Corresponding author
}

Submitted: 31 January 2019 | Accepted: 22 April 2019 | Published: 27 June 2019

\begin{abstract}
This article examines the different ways in which local civil society has responded to refugees and asylum seekers in different parts of Wales in the wake of the recent "refugee crisis". While the events of summer 2015 have generated a considerable amount of scholarly attention, including empirical accounts that look into local community responses to refugees and asylum seekers, the current research has tended to overlook the significance of place and the varied impact of "refugee crisis" across localities; this article aims to fill this gap in the existing research. It draws on findings from qualitative research carried out between 2017 and 2018 with refugee-supporting organisations based in three different locations in Wales. Taking a comparative look at these organisations, the article sheds light on the intensity and variation of civil society response in each of these localities, showing how this is informed by and closely interweaved with processes of place-making and place-framing, contributing to the reshaping of civil society networks and population profiles in these local areas. In conclusion, the article argues that humanitarian responses to "refugee crisis" can be understood not only as instances of hospitality and solidarity but also as practices of locality production.
\end{abstract}

\section{Keywords}

asylum seekers; local civil society; place-making; refugees; solidarity; Wales

Issue

This article is part of the issue "The European Refugee Controversy: Civil Solidarity, Cultural Imaginaries and Political Change", edited by Gert Verschraegen (University of Antwerp, Belgium) and Robin Vandevoordt (University of Oxford, UK/University of Antwerp, Belgium).

(C) 2019 by the authors; licensee Cogitatio (Lisbon, Portugal). This article is licensed under a Creative Commons Attribution 4.0 International License (CC BY).

\section{Introduction}

The dramatic increase in the numbers of displaced people arriving in Europe from 2015 onwards has reignited debates around migration and the appropriate response of European states to the "refugee crisis", including the problematic representation of refugees and migrants in political, media and academic discourses that followed this so-called crisis (Crawley \& Skleparis, 2018; Holmes \& Castañeda, 2016). This has been most prominently articulated at national scales, with discussions in pol- itics and the media over immigration policies (Barlai, Fähnrich, Griessler, \& Rhomberg, 2017) but is also manifested in the practical actions of civil society groups in localities where refugees and asylum seekers are settled, and where they come into contact in everyday life with established local residents. Whilst national debates around refugees have frequently been co-opted by xenophobic, anti-immigration sentiments (e.g., Krzyżanowski, 2018; Narkowitcz, 2018), at a local scale occasional expressions of defensive localism have been balanced by more humanitarian responses, including proactive initia- 
tives by civil society groups to reach out to and welcome refugees to their communities-especially following dissemination of the emotive image of toddler Alan Kurdi on Turkish beach in late 2015 (Sohlberg, Esaiasson, \& Martinsson, 2018).

Local responses to the "refugee crisis" have emerged not only in localities close to major refugee transit routes or critical borders, such as towns in southern Germany that have accommodated thousands of new refugee arrivals since 2015 , but also in places further removed from the main gateways, where refugees and asylum seekers have been settled. Indeed, one of the features of the socalled refugee crisis in Europe is that refugees and asylum seekers have been more widely dispersed geographically, including into localities with limited previous experience of hosting refugees, or indeed of any substantial immigration (Challinor, 2018). In Britain, for instance, the government announced new measures in 2014 and 2016 that allowed the spatial dispersal of mainly Syrian refugees to any localities in the UK, thus marking a shift from previous asylum policy that saw asylum seekers only dispersed to major cities/urban areas of the country (Piacentini, 2012). Under the UNHCR Syrian Vulnerable Persons Resettlement Programme, which was launched in 2014, the UK government invited "any local authority" in the UK to participate in the Programme by bringing in those deemed "in the greatest need" of protection and helping them settle in these localities (Home Office, 2017). In addition, through the launch of Community Sponsorship Scheme in 2016, the government extended the list of actors who could take on the role of bringing in and supporting refugees from local authorities to "community groups including charities, faith groups, churches and businesses" (UK Government, 2016). As a result, the geography of refugee settlement in the UK expanded from urban areas to include rural districts in the Scottish islands and west Wales.

The dispersal of Syrian refugees in part followed from grassroots pressure in the localities concerned, reacting to transnational news reportage and seeking to be part of a collective humanitarian effort. Through such initiatives, the settlement of refugees and asylum seekers has become part of the articulation and negotiation of place identity. The arrival and integration of refugees in a locality contributes to the sense of place, as with any migrant group, as new arrivals introduce new cultural practices, languages, religions and traditions, foods and clothes and other artefacts, and forge new connections with different parts of the world. At the same time, sense of place is also evoked and reproduced through the actions of established local residents as they engage with refugees and asylum seekers, reflecting the ethos and outlook of the community and drawing on local cultural and institutional resources. As such, understanding the relationships between place and civil society responses to the "refugee crisis" is important to explaining the variegated geography of refugee integration; as well as the geography of anti-refugee opinion. Further- more, recognizing the attributes of place that foster and support attitudes of hospitality towards refugees could help to produce strategies for effective social inclusion and integration.

This article examines the significance of place in civil society responses to refugees, and the contribution of these responses to place-making, in three localities in Wales: the small university town of Aberystwyth in mid Wales, the suburban community of Mumbles on the fringe of Swansea, and the inner city neighbourhood of Splott in Cardiff. The study draws on interviews conducted with civil society activists and local councillors in the three localities, participant observation and analysis of press reports, social media and other documents, informed by theories of relational place-making in human geography. The next section introduces the relational place-making literature and reviews previous writing on refugees and place, before the methods are described in more detail and the case studies presented and discussed.

\section{Relational Place-Making and Local Responses to Refugees}

Following the seminal work of Massey $(1991,2005)$, a relational perspective understands places as constellations of "social relations, meeting and weaving together at a particular locus", or "articulated moments in networks of social relations and understandings" (Massey, 1991, p. 28) that transcend the specific space and scale that the "place" is perceived to occupy. Accordingly, places are made and remade; made materially by the bringing together of variously physical components, but also made discursively through the framing and description of particular spatially-located bundles of entities and relations as having a coherence and a collective identity that is distinct from other adjacent bundles (Martin, 2003; Massey, 1991; Pierce, Martin, \& Murphy, 2011). Through these processes, places acquire material and imagined coherence that allows them to focus as the locus for collective action (Jones \& Woods, 2013).

A critical contribution to place-making is made by civil society as it structures collective action and social mobilization around notions of place. These notions are articulated through "place-frames" that "describe common experiences among people in a place, as well as imagining an ideal of how the neighborhood ought to be" (Martin, 2003, p. 733, emphasis in original). Place-frames can therefore be normative or aspirational, such that place-framing is inherently political (Zhang, 2018). They "define the scope and scale of the shared neighborhood of collective concern" (Martin, 2003, p. 733), and may be mobilized proactively to promote forms of progressive social action, or reactively against perceived threats.

The mobilization of various place-frames in civil society responses to migration has been especially notable in questions of the reception and integration of refugees and asylum seekers, as recorded in a number of recent 
studies. Some of this emerging research has focused on issues around hospitality and social encounters between refugees and local population (Challinor, 2018; Wilkinson, 2018), but here the localities and neighbourhoods in which refugees have come to live have been often taken for granted or treated as mere contextual (back)ground. Other studies, on the other hand, have highlighted the significance of place in shaping refugees and migrants integration and experiences in "host" society (McDaniel, 2018; Radford, 2017; Schmidtke, 2018; Vallaster, von Wallpach, \& Zenker, 2018; Woodrow, 2017; Woods, 2018). These cases are varied, but examination of reported cases reveals three broad underpinning factors.

First, the mobilized place-frames incorporate elements of "ethical place-making" (Eckenwiler, 2018), in which places are understood not as autonomous, but as enmeshed in wider networks of affective relations and thus as subject to geographies of responsibilities (Massey, 2004). Framing places in this way thus resonates with Massey's (1991) "global sense of place", and Amin's (2004) "politics of connectivity", promoting "a politics that looks beyond the gate to strangers without" (Massey, 2004, p. 17). Part of this approach is recognizing that whilst individuals identify with a place as part of their collective identity, they are also part of wider shared humanity that transcends place (McDaniel, 2018). The enactment of responsibilities towards refugees and asylum seekers hence commonly starts with a response to global events, transmitted through transnational media, and a compulsion to humanitarian action that is not necessarily place-bound. Such individual humanitarian impulses convert to grounded actions within specific places in which people meet, interact and organize, and particularly in which they may encounter refugees and asylum seekers at the personal level (Hebbani, ColicPeisker, \& Mackinnon, 2017; Huizinga \& van Hoven, 2018; Schmidtke, 2018).

Secondly, collective action is mobilized within places because they offer an appropriate scale at which regular direct participation by volunteers can be organized, and shared interests and identities defined. Whilst new civil society groups may be formed, localities also commonly have an established cohort of civil society groups with dispositions towards humanitarian action, such as churches and trades unions, whose resources and networks may be enrolled. These connections may also be made with local government institutions, with civil society groups lobbying authorities to act practically or symbolically (McDaniel, 2018). At the same time, civil society groups may be mobilized to fill gaps in local government provision or response, for instance by directly sponsoring refugees (Schmidtke, 2018).

Third, place-based responses to the global issue of refugees necessarily involves a negotiation of scale. Notably, the assertion of progressive, humanitarian values in the framing of places may conflict with the immigration policies of the nation state. As such, the artic- ulation of place identity in designations such as "welcoming cities" and "cities of sanctuary" may be statements intended to differentiate cities and towns from the discursive position of the nation (McDaniel, 2018). In the United States, "cities of sanctuary" are primarily places supporting undocumented immigrants against the enforcement regimes of the nation state; whereas in Europe "cities of sanctuary" tend to be framed as offering safety to refugees. Similarly, the mobilization of civil society groups working in place to support refugees and asylum seekers may be framed as resistance to state border regimes, though as Obradovic-Wochnik (2018, p. 65) remarks, their work "sometimes unwittingly supports the rationalities of government through the focus on counting refugees or working with state [agencies]".

The studies engaged in the above discussion provide insights into local civil society responses to refugees and asylum seekers, but it is unclear how representative they are of broader experiences. Most of the studies are single case studies and whilst common threads can be identified, they are mostly places characterized by prominent and visible community action to support refugees. This article hence aims to develop the strand of research through comparative analysis of three localities, which exhibit different forms and degrees of civil society mobilization in response to refugees and asylum seekers. The analysis is informed by the three themes identified in the discussion above; they provide a guiding framework for understanding the role of place and the relationship to place and scale for these local civil society organisations. By focusing on how organisations frame their work, how they draw on certain understandings, experiences and perceptions of place, be this their locality or more global imaginaries, we are able to tease out the role of place in shaping local civil society whilst also exploring the changing nature of locally based action in response to global issues.

\section{Methods and Case Studies}

The research for this article was conducted as part of a wider study of the changing nature of local civil society in Wales, UK and how the imaginaries and practices of local civil society have been stretched and reconfigured by global interconnectivity. The comparative case study analysis presented in this article specifically responds to the research question asking to what extent do patterns of participation in local civil society, and the engagement of local civil society with global issues, vary between localities, and how is this influenced by geography, class and ethnic composition? The three case study locations-Aberystwyth, Mumbles, and Splott-were selected as indicative of different geographical contexts, socio-economic profiles and histories of civic and civil society activity, but not initially with specific regard for questions of refugees and asylum seekers.

Aberystwyth is a university town of around 19,000 people in mid Wales that functions as a service centre 
for the surrounding rural region. It has a long civic history and a well-defined local civil society with a diverse range of organizations. The presence of the university contributes to attracting international visitors and $\mathrm{mi}-$ grants to the town, and in the 2011 Census $13 \%$ of the population were born outside the UK. Just under a third of residents can speak Welsh. Politically, Aberystwyth leans to the centre-left, with elections dominated by the Liberal Democrats and the Welsh nationalist party Plaid Cymru, and the town has a history of radical political activity in struggles around Welsh national identity (Jones \& Fowler, 2008).

Mumbles is an affluent suburban and seaside village with a population of around 14,000 people, situated on the western side of Swansea Bay. It forms part of the Swansea conurbation and the Swansea city local authority area, with most employed residents commuting to work in the city but has a strong sense of independent identity and an active distinct local civil society. It was described as the "best place to live in Wales" by the Sunday Times newspaper in 2018. The population is predominantly white British, with little ethnic diversity, and primarily votes Conservative-the party holding three of the four city council wards, and half of the seats on the community council.

Splott is an inner-urban neighbourhood, located to the east of Cardiff city centre, with a population of around 13,000 residents. A traditional working class district, it has relatively high levels of deprivation and is one of the most ethnically diverse parts of Cardiff, with $17.4 \%$ of residents recorded as non-white in the 2011 Census, and $13.6 \%$ born outside the UK. The neighbourhood has a strong sense of identity, reinforced by hyper-local media, but civil society activity is largely organized at the city scale or across the adjacent neighbourhoods of Adamsdown, Roath and Tremorfa. Splott ward of Cardiff City Council persistently elects Labour councillors.

In order to address the broader research interest of how local civil society organisations respond to global concerns, the research conducted a survey of civil society organisations and groups based in the three localities whose work focused on responding to the refugee and migration crisis. Interestingly, the study found refugeesupporting organizations and groups existing in all these three relatively small locations: these were Aberaid in Aberystwyth, Bloom in Mumbles, and Oasis and Space4U in Splott. These active organisations were identified through local print and social media as important actors in the civil society landscape of each place. This was further supported through local knowledge and interviews with local councillors and other key stakeholders in the three areas. These organizations were positioned as the focal points of the research, with additional data collection radiating out from these.

Interviews with 41 individuals were conducted between December 2016 and November 2018 with representatives and members of these and other civil society organizations, along with councillors and other key local stakeholders in the three areas. The demographic features of the interviewees varied in relation to age and gender; the sample included 23 women and 18 men, ranging from 26 to 73 years of age. Some of the interviewees were employed by the organizations in which they were involved in, many others were just volunteers. The interviews were semi-structured and sought to gain an understanding of the organizations in which these individuals were involved in as well as of their own motivations and experiences of volunteering/working for these civil society groups. Interviews included questions, inter alia, about the goals of the organization, how it originated, its relationship to the place in which it was based, who was involved and in what capacity, and specific questions around how it used social media to engage with different audiences. The interviews also included questions about the perceived levels of awareness of global issues, such as the "refugee crisis", in the area, how local people had responded to the issue and finally a broader discussion of the nature of local civil society in the locality and how it may have changed over time. They were recorded, transcribed and coded using NVivo software; and were supplemented by the collection and analysis of data from press reports, websites, social media (including Facebook and Twitter), and other documents, as well as by ethnographic observation at meetings and events.

\section{Refugee Support Action in Three Welsh Places}

\subsection{Local Responses and National Narratives}

Between September 2015 and November 2017, at least 725 refugees from Syria were resettled in Wales under the UK Government's Syrian Vulnerable Persons Resettlement Programme (SVPRP), joining nearly 3,000 asylum seekers of a range of nationalities resident in Wales whilst awaiting the outcome of asylum applications, and an estimated 6,000 to 10,000 earlier refugees from various countries (including previous asylum seekers with approved applications) that had settled in Wales (Houghton, 2017; National Assembly for Wales, 2017). Whilst the distribution of asylum seekers followed established UK government policy in being concentrated in the urban areas of Cardiff, Newport, Swansea and Wrexham (National Assembly for Wales, 2017), Syrian refugees brought to Wales from camps in the Middle East under the SVPRP were, as in England and Scotland, dispersed more widely to volunteering local authorities. By November 2017, all but two of the 22 local authorities in Wales had accepted refugees under the programme (Houghton, 2017).

Ceredigion was one of the first local authorities in Wales to apply to take Syrian refugees under the expanded SVPRP scheme in 2015, following pressure from within the local community that reflected a wider local civil society mobilization in response to the "refugee crisis", including the formation of Aberaid in 2015 as an informal fundraising network. Aberaid has subsequently 
worked with Ceredigion Council and other groups and agencies in providing support for the refugee families settled in Aberystwyth, whose numbers increased from an initial 11 refugees in December 2015 to a total of 33 refugees living in the town in May 2018. Additionally, Aberaid has raised $£ 20,000$ to directly sponsor a refugee family under the UK Government's Community Sponsorship Scheme, which seeks to extend responsibility for hosting refugees from the state to civil society. Although not the first community sponsorship project in Wales-Narbeth, in Pembrokeshire, had welcomed a Syrian family under the scheme in July 2017-Aberaid's activity is perceived as "pioneering", and Aberystwyth hosted a one-day conference on the Community Sponsorship programme in July 2017, including speakers with experience of Canada's private sponsorship scheme (cf. Schmidtke, 2018).

In contrast, the settlement of Syrian refugees in Cardiff has continued an established process of housing asylum seekers and refugees in the city. Although refugees and asylum seekers may be dispersed across the city, relatively low property and rental prices in Splott have led to a clustering of refugees and asylum seekers in the neighbourhood, which also hosts two civil society run support centres. Oasis and Space4U were both established by volunteers in 2008 and operate as day centres and community spaces for refugees and asylum seekers, providing services and facilities including English lessons, advocacy and employment advice, free lunches and leisure spaces. They are used by individuals from a range of national backgrounds, notably Eritrea, Sudan, Iran and Iraq. In comparison with Aberaid, the emphasis is less on direct participation in refugee resettlement, and more on promoting integration and social inclusion and creating "third places" in which refugees and asylum seekers can meet in accessible, neutral, comfortable and welcoming settings (Huizinga \& van Hoven, 2018). As such, whilst located in Splott, both centres serve the wider city and engage volunteers from across the city, and although the 2015 "refugee crisis" brought them more attention it did not substantially change their work.

Mumbles, meanwhile, is distinct from the other two case studies in not directly hosting refugees or asylum seekers, however local residents formed a refugee support group, Bloom, in response to the 2015 "refugee crisis", which is active in befriending refugees and asylum seekers living elsewhere in Swansea, and in awareness raising activities including school visits, food nights and multicultural events. Similarly, activists resident in Mumbles played a key role in establishing the Swansea City of Sanctuary initiative:

Swansea was the second City of Sanctuary in the UK, recognised in 2010, first in Wales and it's been a really strong group ever since. There's about 100 pledged organisations in Swansea who are active to more or less degree depending....We have a manage- ment committee made up of both sanctuary seekers, asylum seekers and refugees and people from the local community. And I guess relevant to your research is that in Swansea the co-founders of Swansea City of Sanctuary were and are still living in Mumbles. It's an idea that actually came from them. (Swansea City of Sanctuary representative, Swansea, interview)

Both existing initiatives such as Swansea City of Sanctuary, Oasis, etc., and the new local groups such as Bloom and Aberaid that have emerged in response to the 2015 "refugee crisis" play an important role not only in offering support to refugees and asylum seekers living in Wales but also aiming to put into practice the idea of Wales as a "welcoming place". Following the "crisis" Wales has sought to reposition and promote itself as a welcoming place for refugees and asylum seekers; most notably, this culminated in the recent introduction of the "Nation of Sanctuary-Refugee and Asylum Seekers Plan" by the Welsh Government, setting out its ambition to make the country the first "nation of sanctuary" in the world for refugees and asylum seekers (Welsh Government, 2019). The Plan can also be seen as an example of how positive narratives about refugees can be mobilised at the national level and be employed as nation-building processes (cf. Giudici, 2014). The positive and inclusive language promoted by the Welsh Government is often contrasted with the rather hostile approach adopted by the UK government with regard to immigration. While immigration and nationality are matters reserved to the UK government and parliament, Wales as a devolved nation has competence in a range of fields affecting refugees and asylum seekers' everyday lives such as education, healthcare, and housing. Yet these positive narratives and ideas remain largely on the discursive level as they do not seem to have impacted significantly on people's attitudes on the ground; in terms of anti-immigration sentiments, there is relatively little difference between Wales and England as the result of the recent EU referendum has shown.

\subsection{Motivations and Framing}

The "European refugee crisis" in 2015 marked a pivotal moment for civil society mobilization towards refugees in the case studies. Aberaid and Bloom both originated in emotive responses to media portrayals of Syrian refugees, and especially the photograph of drowned toddler Alan Kurdi:

I started...it was about two and a half years ago now. I saw a picture of Alan Kurdi who was the little boy who got washed up on a beach in Turkey, and that deeply affected me, seeing that picture. I've got two little boys. One of them was around the same age and I couldn't imagine how scared I'd have to be to risk that happening to my son.... I was just working in a pub down the road as a barmaid. So it was completely 
out of the blue...it changed my life. (Bloom founder, Mumbles, interview)

The emotive connection as a "mother" made with events in the Mediterranean or continental Europe fed into motivations to help in those places, a reaction which had the transformation effect of turning the above interviewee from an ordinary working individual into a civil society activist. Aberaid was set up by six "young mothers" connecting through Facebook and initially operating as an informal group fundraising for refugees in camps in Greece and Calais. The founder of Bloom similarly first travelled to Calais to volunteer in the "Jungle" refugee camp before starting to organize activities in Swansea after meeting a Syrian refugee through working at a food bank.

In Aberystwyth the catalyst for refocusing civil society engagement with refugees within the locality was provided by the UK Government's expansion of the SVPRP in 2015 and its call for local authorities to host refugees, as noted earlier. A grassroots movement developed to lobby the local Ceredigion Council to agree to take refugees, gaining traction with the local community and with council members because the idea resonated with a shared place-frame of Aberystwyth as a progressive, outward-looking, international town. As one councillor put it, "it's that kind of place here" (Fieldnotes, July 2017). The framing of Aberystwyth in this way drew on the presence of the university and the international networks of staff and students, as well as perceived high levels of political interest and awareness of international events, and a history of outward-looking environmental, peace and trade justice activism (with the small size of the town further meaning that key individuals were active across multiple civil society groups). The inclusive culture articulated in the place-frame was mobilized not only through direct participation in Aberaid's work with refugees and contributions to fundraising, but also through rallies and marches demonstrating solidarity with refugees and with civilians in Syria. The settlement of 33 refugees in the town and public support for the community sponsorship proposal, as well as positive coverage in national press and broadcast media, further reproduced and perpetuated the dominant place-frame, with interviewees citing accolades of Ceredigion Council as a "trailblazer" and pride in Aberystwyth as "one of the first towns" to welcome Syrian refugees as proof of its liberal, progressive identity.

Although Bloom in Mumbles started from a similar response to the "refugee crisis" as Aberaid, the development of its local activities followed a very different trajectory. In part this reflected the existing presence of refugees and asylum seekers in Swansea, with whom connections could be built and for whom activities could be organized. There was therefore less incentive to mobilise to bring refugees to Mumbles. Indeed, as noted earlier, although individuals from Mumbles are active in Swansea-wide organizations including Bloom and City of Sanctuary, that this activism has not translated into moves to host refugees in Mumbles is indicative of a shared place-frame of Mumbles as a conservative place, constrained by limited exposure to other cultures:

There's a lot of goodwill in Mumbles [but] it doesn't always translate to being actively welcoming. It's quite difficult to put some of these things into words, but for example a good number of our volunteers come from Mumbles, they live there. And they're talking to their neighbours and their friends about what they're doing. That is a level of awareness. But you know if an asylum seeker were to get on the bus and get off in Mumbles would they be welcomed? I don't know. (Civil society activist (1), Mumbles, interview)

I just think they haven't been exposed to refugees. So they are friendly but they need a bit of education and to meet people. I think that's why the popup nights are hugely successful here. I think people would be good but they just don't get much opportunity, because there's no asylum seeker housing down this side of Swansea. (Civil society activist (2), Mumbles, interview)

In Cardiff, Oasis and Space4U were formed long before the 2015 "refugee crisis" and responded primary to local issues, such as lack of support, poor accommodation, rise in destitution among asylum seekers-issues which were a product of an increasingly restrictive and hostile UK asylum policy (Parker, 2018) - rather than global concerns. As such, they arguably were motivated by normative place-frames of how social relations in Cardiff ought to be and mobilized to fill gaps in provision that militated against this vision. The most significant placeframes for Oasis and Space4U were hence those articulated for Cardiff as a city, e.g., as being welcoming, multicultural and, as one interviewee put it, "less racist", rather than more immediately for the neighbourhood of Splott. They saw their location in Splott mainly as a matter of convenience, rather than an expression of neighbourhood identity, and efforts to attract local residents into the centres as visitors or volunteers were described as difficult. At the same time, the presence of these two organisations was valued by other local groups in Splott which saw them as adding to the local dynamism and diversity. Although dynamics of engagement with local residents were altered by the public's shifting interpretative frames of refugees with the Syria crisis, the latter did not substantially change the work of Oasis or Space4U; while it made them more visible to city residents and brought offers of help and donations, such rise in interest was short-lived and focused mainly on Syrian refugees, even though, as noted earlier, the latter were not necessarily a major client groups for these organisations:

One of the things I'd say about the refugee crisis is that we were getting lots of offers of support, more at that time. Mostly positive, but sometimes it was quite 
strange that people would only be willing to give to help Syrian refugees. We kindly had to say quite often that we support asylum seekers and refugees from all over the world. Is it okay if your donation goes to them, not just the Syrian refugees? Most people said yes, but a couple of people said no, they only wanted it to go to Syrian refugees, which was a bit strange. (Space4U volunteer, Splott, interview)

\subsection{Civil Society Infrastructure and Negotiating Scale}

All four of the core organizations that we studied work closely with other civil society groups and public agencies, including local government. Although studies elsewhere have sometimes identified tensions between the objectives of civil society groups working with refugees and local government (McDaniel, 2018), in Wales the roles have tended to be complementary. In Aberystwyth, in particular, civil society mobilization to support refugees needed to enrol the local Ceredigion County Council as it was the council that was required to apply to take refugees; in turn, once the council had agreed this, it formed a partnership with Aberaid and other civil society groups in order to have the capacity to house and support refugees. Only with the advent of the Community Sponsorship scheme has Aberaid been able to apply to sponsor refugees directly:

Lots of churches have been very helpful and also the flat we now have, sort of, reserved for this [Syrian] family, it actually belongs to a local church. So several churches have been helpful. Other organisations, Amnesty International, Freedom from Torturethey're also local organisations-they've been quite helpful. But then also things that l'd say not quite so closely connected, like walking groups or something. They've done walks and then fundraised money. So that's all been quite positive. I have to say, generally the local politicians as well. So the Town Council, Aberystwyth Town Council has been supportive, although they don't have much budget or anything like that. Ceredigion they had to prove with Ceredigion County Council. So we actually went to their scrutiny committee meeting. Well it was approved with, like, sort of four abstentions or something. So most people are clearly quite...they're very, very supportive. (Aberaid representative, Aberystwyth, interview)

As the quote above indicates, Aberaid engaged with and received support from a wide range of local organizations, groups and actors. The geographies of these groups and organizations have shaped the spatialities of civil society mobilization in support of refugees in the case studies. In Aberystwyth, the groups engaged have tended to be concentrated in the town, reflecting its status of the main town in the county, and reinforcing the identification of the mobilization with the town. Bloom in Swansea, and Oasis and Space4U in Cardiff, however, work with civil society groups operating across the city, not just in the specific neighbourhoods of Mumbles and Splott. At the same time, the organizations are grounded in place by the use of buildings and facilities, often volunteered by civil society groups. The location of Oasis in Splott, for example, largely stems from being approached by a Methodist congregation looking to rent out a surplus chapel; whilst Bloom's ties to Mumbles are reinforced by the use of facilities at an evangelical church.

This movement between neighbourhood and city, or town and county, is one of the ways in which the refugee support groups negotiate scale. In Cardiff, Oasis and Space4U are primarily framed as city-wide, or even as Welsh, organizations that happen to be based in Splott. In Swansea, individuals living in Mumbles have set up groups such as Bloom and City of Sanctuary working across the city, but also feel obliged to be active in Mumbles through fundraising and raising awareness. In Aberystwyth, meanwhile, support for refugees is strongly framed as an expression of the town community, though involving volunteers from the rural hinterland, but has by necessity had to enrol the wider county council-a step that involved persuading rural councillors with more conservative inclinations to support the initiative.

Beyond the locality, working with refugees necessarily involves encountering the apparatuses of the nation state. In contrast again to some cases recorded elsewhere in the literature, none of the organizations studied positioned themselves as resisting the UK immigration regime, although individuals were critical of policies, but the work of each was informed by immigration legislation and involved contact with various agencies. Aberaid's application to the Community Sponsorship scheme required negotiation of UK Home Office bureaucracy and civil servants at different levels, with volunteers contrasting positive support from the Home Office team in Wales with "unhelpful" officials in London. Local civil society mobilizations for refugees developed networks of support and mutual exchange of advice informally and through organizations such as CitizensWales and Cities of Sanctuary Wales, as well as by working with national civil society groups such as the British Red Cross; whilst translocal support was also engaged through social media, with Bloom for instance reporting receiving donations from fund-raising by churches in London.

Finally, the transnational mobility of refugees and asylum seekers gives any local action an international dimension. The place-based actions of volunteers were accompanied by awareness and concern in interview discussions about details of the war in Syria; in Aberystwyth, both refugees and supporters have periodically joined local peace activists in demonstrations against the Syrian war. There is awareness too of local issues of refugee reception and integration as part of an international crisis. Individuals from Aberaid have continued to visit refugee camps in Calais after the organization's main focus has oriented to the town, whilst Oasis and Space4U 
are involved with activities such as publishing refugee stories and running exhibitions that articulate global connections. Transnational connections have also sought to learn from experiences elsewhere, for example through the involvement of Canadian participants in a conference on Community Sponsorship of refugees in Aberystwyth, and contacts between Swansea City of Sanctuary and the North American sanctuary movement.

\section{Conclusion}

Civil society groups in Wales, as across Europe, mobilized in response to the 2015 "refugee crisis". Initial motivations to help with an apparently distant problem-in the eastern Mediterranean or the "Jungle" camp in Calaiswere converted into more local, place-based action, involving receiving refugees from Syria into local communities and/or supporting refugees and asylum seekers from Syria and elsewhere already living in the locality. As has been documented in other recent studies in Europe, North America and Australia (McDaniel, 2018; Radford, 2017; Schech, 2014; Schmidtke, 2018; Vallaster et al., 2018; Woodrow, 2017; Woods, 2018), local civil society actions to support refugees and asylum seekers in Wales have drawn on place-frames to mobilize volunteers and structure initiatives, enrolled local government and other civil society groups to build capacity, and negotiated across scales to engage state immigration regimes and to share support and experiences. However, as a comparative study of three communities-Aberystwyth, Mumbles and Splott-this article has been able to move beyond other literature that has focused on a single case study by exploring the differential mobilizations of civil society towards refugees and asylum seekers in these localities, and how they produced and reproduced these places and neighbourhoods.

In Aberystwyth, a dominant framing of the town as a liberal, open and internationalist place was effectively employed to mobilize civil society actors that enjoyed relative autonomy and coherence in a freestanding small town to become an early recipient of Syrian refugees and a "pioneer" in the Community Sponsorship scheme, despite not having hosted refugees or asylum seekers for forty years. These mobilizations thus reaffirmed the neighbourhoods' self-image as a progressive place, while at the same time generating new narratives and images, e.g., as a "first town in Wales" to welcome Syrian refugees, a "pioneer" in the field, etc. This reminds of Appadurai's (1996) insight that place-making/locality production is simultaneously context driven and context generating. By comparison, responses to the "refugee crisis" in Mumbles were not as intensive as in Aberystwyth but still significant; while in the case of the latter such responses became part of local community-building, in Mumbles they were channelled towards helping refugees and asylum seekers already living in neighbouring Swansea, with activities in Mumbles itself tempered by its framing as a more conservative community and culturally backward where attitudes towards refugees seemed ambivalent. These mobilisations thus enabled the opening up of new connections between this area and the neighbouring city of Swansea. In addition, they also provided an opportunity for civil society activists to challenge the existing place-frames and contexts in Mumbles, creating new possibilities for the neighborhood to reflect on its image as a "closed village" towards a more open and inclusive neighborhood, e.g., through meetings and encounters between the local population and refugees and asylum seekers which were described as "educating" practices. This was reflected in narratives among the interviewees such as "Mumbles is slowly changing" or "It is getting there". Both these situations contrasted with Splott, where the major impact of the 2015 crisis was short-lived rather than lasting in terms of the increase in public support for the existing work of organizations such as Oasis and Space4U with asylum seekers and refugees in the area.

Accordingly, civil society responses in each of these localities has contributed to ongoing place-making. These include, inter alia, the formation of new local groups and reshaping of civil society networks, the emergence of new activities, connections and narratives, the rise in awareness among the local community, the changing of local population profiles, the transformation of local subjects into activists, etc. Through the discussion of these changes, the analysis has shed light on the intensity and variation of these mobilisations in each of these localities, demonstrating how humanitarian responses to "refugee crisis" are not only about practices of hospitality and solidarity but also about the production of localities in which these activities take place.

\section{Acknowledgments}

This work was funded by the Economic and Social Research Council, UK under Grant ES/L009099/1.

\section{Conflict of interest}

The authors declare no conflict of interests.

\section{References}

Amin, A. (2004). Regions unbound: Towards a new politics of place. Geografiska Annaler, 86(1), 33-44. https://doi.org/10.1111/j.0435-3684.2004.00152.x

Appadurai, A. (1996). The production of locality. In D. Gaonkar \& B. Lee (Eds.), Modernity at large: Cultural dimensions of globalizations (pp. 178-199). Minneapolis, MN: University of Minnesota Press.

Barlai, M., Fähnrich, B., Griessler, C., \& Rhomberg, M. (2017). The migrant crisis: European perspectives and national discourses. Zurich: LIT Verlag.

Challinor, E. (2018). Refugee hospitality encounters in northern Portugal: "Cultural orientations" and "contextual protection". Migration and Society, 1(1), 
96-110.

Crawley, H., \& Skleparis, D. (2018). Refugees, migrants, neither, both: Categorical fetishism and the politics of bounding in Europe's 'migration crisis'. Journal of Ethnic and Migration Studies, 44(1), 58-64.

Eckenwiler, L. (2018). Displacement and solidarity: An ethic of place-making. Bioethics, 32, 562-568.

Giudici, M. (2014). Immigrant narratives and nationbuilding in a stateless nation: The case of Italians in post-devolution Wales. Journal of Ethnic and Racial Studies, 37(8), 1409-1426.

Hebbani, A., Colic-Peisker, V., \& Mackinnon, M. (2017). Know they neighbour: Residential integration and social bridging among refugee settlers in Greater Brisbane. Journal of Refugee Studies, 31, 82-103.

Holmes, S. M., \& Castañeda, H. (2016). Representing the "European refugee crisis" in Germany and beyond: Deservingness and difference, life and death. American Ethnologist, 43(1), 12-24.

Home Office. (2017). Syrian vulnerable persons resettlement scheme (VPRS): Guidance for local authorities and partners. London: UK Government Publications. Retrieved from https://assets.publishing.service. gov.uk/government/uploads/system/uploads/ attachment_data/file/631369/170711_Syrian_ Resettlement_Updated_Fact_Sheet_final.pdf

Houghton, T. (2017), December 26$)$. This is how many refugees have been resettled in Wales over the past year. Western Mail. Retrieved from https://www. walesonline.co.uk/news/wales-news/how-manyrefugees-been-resettled-14055878

Huizinga, R. P., \& van Hoven, B. (2018). Everyday geographies of belonging: Syrian refugee experiences in the Northern Netherlands. Geoforum, 96, 309-317.

Jones, R., \& Fowler, C. (2008). Placing the nation. Cardiff: University of Wales Press.

Jones, M., \& Woods, M. (2013). New localities. Regional Studies, 47, 29-42.

Krzyżanowski, M. (2018). Discursive shifts in ethnonationalist politics: On politicization and mediatization of the "refugee crisis" in Poland. Journal of Immigrants \& Refugee Studies, 16(1/2), 76-96.

Martin, D. (2003). 'Place-framing' as place-making: Constituting a neighborhood for organizing and activism. Annals of the Association of American Geographers, 93, 730-750.

Massey, D. (1991). A global sense of place. Marxism Today. Retrieved from http://banmarchive.org.uk/ collections/mt/pdf/91_06_24.pdf

Massey, D. (2004). Geographies of responsibility. Geografiska Annaler, 86(1), 5-18.

Massey, D. (2005). For space. London: SAGE Publications.

McDaniel, P. (2018). Shared humanity, city branding, and municipal immigrant integration initiatives in the southeastern United States. Southeastern Geographer, 58, 250-281.

Narkowitcz, K. (2018). 'Refugees not welcome here': State, church and civil society responses to the refugee crisis in Poland. International Journal of Politics, Culture and Society, 31(4), 357-373.

National Assembly for Wales. (2017). 'I used to be someone': Refugees and asylum seekers in Wales. Equality, Local Government and Communities Committee Report. Cardiff: National Assembly for Wales.

Obradovic-Wochnik, J. (2018). Urban geographies of refugee journeys: Biopolitics, neoliberalism and contestation over public space in Belgrade. Political Geography, 67, 65-75.

Parker, S. (2018). "Another home not another place to live": The discursive construction of integration for refugees and asylum seekers in Wales (Unpublished Doctoral dissertation). Cardiff University.

Piacentini, T. (2012). Solidarity and struggle: An ethnography of the associational lives of African asylum seekers and refugees in Glasgow (Unpublished Doctoral dissertation). The University of Glasgow.

Pierce, J., Martin, D. G., \& Murphy, J. T. (2011). Relational place-making: The networked politics of place. Transactions of the Institute of British Geographers, $36,54-70$.

Radford, D. (2017). Space, place and identity: Intercultural encounters, affect and belonging in rural Australian spaces. Journal of Intercultural Studies, 38, 495-513.

Schech, S. (2014). Silent bargain or rural cosmopolitanism? Refugee settlement in regional Australia. Journal of Ethnic and Migration Studies, 40, 601-618.

Schmidtke, O. (2018). The civil society dynamic of including and empowering refugees in Canada's urban centres. Social Inclusion, 6(1), 147-156.

Sohlberg, J., Esaiasson, P., \& Martinsson, J. (2018). The changing political impact of compassion-evoking pictures: The case of the drowned toddler Alan Kurdi. Journal of Ethnic and Migration Studies. https://doi. org/10.1080/1369183X.2018.1538773

UK Government. (2016). Community sponsorship scheme launched for refugees in the UK. UK Government. Retrieved from https://www.gov.uk/ government/news/community-sponsorshipscheme-launched-for-refugees-in-the-uk

Vallaster, C., von Wallpach, S., \& Zenker, S. (2018). The interplay between urban policies and grassroots city brand co-creation and co-destruction during the refugee crisis: Insights from the city brand Munich (Germany). Cities, 80, 53-60.

Welsh Government. (2019). Nation of sanctuary: Refugee and asylum seeker plan. Cardiff: Welsh Government. Retrieved from https://gweddill.gov. wales/docs/dsjlg/publications/equality/190128refugee-and-asylum-seeker-plan-en.pdf

Wilkinson, O. J. (2018). "It's being, not doing": Hospitality and hostility between local faith actors and international humanitarian organizations in refugee response. Migration and Society, 1(1), 111-126.

Woodrow, N. (2017). City of welcome: Refugee storytelling and the politics of place. Continuum-Journal of Media and Cultural Studies, 31, 780-790. 
Woods, M. (2018). Precarious rural cosmopolitanism: Negotiating globalization, migration and diversity in Irish small towns. Journal of Rural Studies, 64, 164-176.
Zhang, A. Y. (2018). Thinking temporally when thinking relationally: Temporality in relational place-making. Geoforum, 90, 91-99.

\section{About the Authors}
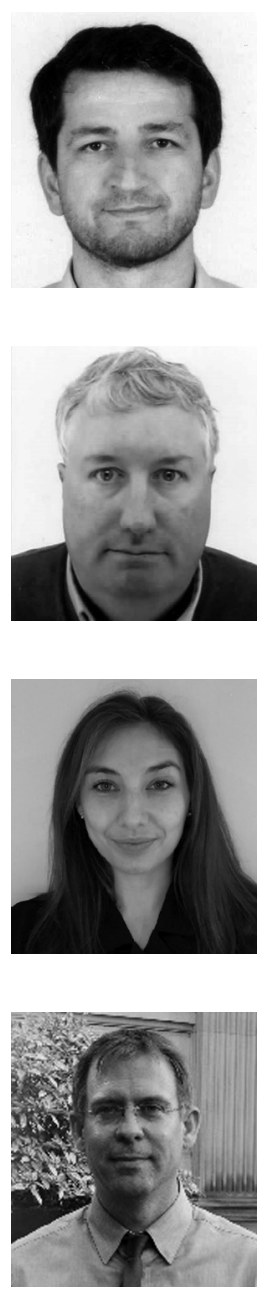

Taulant Guma is Lecturer in Human Geography at Edinburgh Napier University. His research explores a wide range of topics pertaining to migration, including social security and risks, "race" and ethnicity, civil society and participation, globalisation and place, transnationalism and healthcare, online networks and digital communities. Approaching these issues from a multidisciplinary and ethnographic perspective, he has published his work in various peer-reviewed and leading journals such as Journal of Ethnic and Migration Studies, Identities: Global Studies in Culture and Power, Population, Space and Place.

Michael Woods is Professor of Human Geography at Aberystwyth University, UK, and Co-Director of the Wales Institute of Social and Economic Research, Data and Methods (WISERD) and the ESRC WISERD/Civil Society research centre, of which this work formed part. His research interests range across issues of globalization, rural geography, political geography and spatial justice, including projects funded by the European Research Council, UK Economic and Social Research Council (ESRC) and EU Horizon 2020 programme.

Sophie Yarker has a background in human geography and sociology with research interests in community, belonging and civil society. She currently holds the position of Research Fellow at the University of Manchester researching neighbourhood-based approaches to age-friendly cities and communities. Prior to this she has worked as a research associate at Aberystwyth University and as a Teaching Fellow at Newcastle University where she gained her PhD in Human Geography.

Jon Anderson is a Professor of Human Geography at the School of Geography and Planning, Cardiff University, UK. His research interests focus on the relations between culture, place and identity, particularly the geographies, politics, and practices that emerge from these. His key publications include: Understanding Cultural Geography: Places and Traces (2015, 2nd ed.), Water Worlds: Human Geographies of the Ocean (2014, edited with K. Peters), and Page and Place: Ongoing Compositions of Plot (2014). 